\title{
RISK FACTORS FOR SUICIDAL IDEATION AND SELF-HARM AMONG UNDERGRADUATE STUDENTS IN A PRIVATE UNIVERSITY IN OGUN STATE, NIGERIA
}

\author{
Faith A. Johnson, Lolade Ogunsanmi and Israel Ayokanmi \\ Department of Public Health, School of Public and Allied Health, Babcock University, \\ Ilishan Remo, Ogun State, Nigeria
}

Corresponding Author Email: faithalex@outlook.com

\begin{abstract}
Cite this article:
Johnson F.A. , Ogunsanmi L., Ayokanmi I. (2021), Risk Factors for Suicidal Ideation and Self-Harm among Undergraduate Students in a Private University in Ogun State, Nigeria. African Journal of Health, Nursing and Midwifery 4(6), 29-42. DOI: 10.52589/AJHNM02IMTTGX.
\end{abstract}

\section{Manuscript History \\ Received: 13 Oct 2021}

Accepted: 3 Nov 2021

Published: 14 Nov 2021

Copyright $\odot 2020$ The Author(s). This is an Open Access article distributed under the terms of Creative Commons AttributionNonCommercial-NoDerivatives 4.0 International (CC BY-NC-ND 4.0 ), which permits anyone to share, use, reproduce and redistribute in any medium, provided the original author and source are credited.

\begin{abstract}
Background: Today, the most prevalent and the leading cause of death among young people is suicide. Worldwide, suicide accounts for an estimated $6 \%$ of all deaths among young people. The study examined the various risk factors for suicidal ideation and selfharm amongst Babcock University undergraduates. Method: Descriptive survey research design was utilized with a multistage sampling technique to select 398 undergraduates. The instrument for data collection was a semi-structured questionnaire that sought information on the environmental, social, and intrapersonal factors influencing suicide ideation and self-harm. Results were presented via means and percentages for descriptive statistics; correlation and regression were used to determine the associations between suicidal ideation and the risk factors. Ethical clearance was sought from Babcock University Health Research Ethics Committee. Results: The distribution of participants showed that $46.0 \%$ (183) were males while $54.0 \%$ (215) were females. Environmental factors influencing suicidal ideation were computed and measured on a 21-point rating scale with a mean $\pm S D$ of $13.38 \pm 3.458$. The respondents' mean $\pm S D$ for the social factors measured on a 27-point rating scale was 17.15 \pm 5.772 . Correlation analysis showed that suicide ideation had a statistically significant relationship with gender $(p<0.01)$, parents' spousal relationship $(p<0.01)$, environmental $(p<0.01)$, social $(p<0.01)$, and intrapersonal factors $(p<0.01)$. Self-harm had a significant relationship with parents' relationship $(p<0.01)$, environmental $(p<0.01)$, social $(p<0.01)$ and intrapersonal factors $(p<0.01)$. However, the practice of self-harm was not different across the two genders $(p=0.170)$. Conclusion: Suicidal behaviors have been seen to be a serious public health concern. The prevention and intervention programs of suicide and self-harm should consider the particular characteristics of adolescent suicide and self-harm. This should include social transmission and recognition of mental health disorders.
\end{abstract}

KEYWORDS: Suicidal Ideation, Self-harm, Risk Factors, Suicide, Adolescents. 


\section{INTRODUCTION}

Suicidal behaviours (suicidal ideation and deliberate self-harm) have become a significant public health problem among youths worldwide, and it increases the burden of health care. Suicide has been seen as the most common and leading cause of death among young people worldwide (Hawton, Saunders, \& O'Connor, 2012). The World Health Organisation (WHO) estimates that approximately one million people die from suicide each year, which represents a global mortality rate of 16 people per 100,000 or one death every 40 seconds. It is predicted that by 2020 , the rate of death will increase to one death every 20 seconds. Worldwide, suicide accounts for an estimated 6\% of all deaths among young people (Kwangu \& Mwenya, 2017). Suicide among young people is a significant public health concern (WHO, 2016). Also, the Global Burden of Disease Study 2004 estimates that $6 \%$ of all deaths among young people aged 10-24 years worldwide result from suicide. Suicidal behaviors include self-harm, suicidal ideation (thinking about killing oneself), attempting suicide, and suicide itself. Suicidal ideation, according to WHO (2016), often emerges in adolescence and is prevalent among this age group, particularly among females.

Most current definitions of suicide rely on two elements: a precise outcome (death) and a prerequisite - the intention to die (Genevieve, 2016). Attempts to better define suicide have led to the concept of the suicidal process - a sequence that goes from suicidal ideation (ideas/thought) to plan, then to attempt and ultimately death, through a specific action (Bertolote et al., 2009). Therefore suicidal ideation is a lead or a starting point to self-harm and suicide. Suicidal ideation and self-harm have been predictors of suicide, thereby increasing the mortality rate of individuals in countries bringing pain, agony, and tears to the face of everyone. There are risk factors that young people are exposed to that lead to this ideation or harm e.g., bullying. Those who attempt suicide and survive may have severe injuries like a broken bone, brain damage, or organ failure. Significant contributors to self-harm and suicidal ideation could be several environmental, psychosocial and behavioral factors. Other factors include genetic vulnerability and psychiatric, environmental, psychological, familial, social, and cultural factors (Hawton, Saunders, \& O'Connor, 2012). Physical, sexual, and emotional abuses have also been associated with adolescent suicidal ideation and attempt. According to Miller et al. (2013), it was identified that suicidal behaviors also exist together with other health risk behaviors such as smoking, aggressive behaviors, illicit drug use, alcohol use, and experience of sexual intercourse. Those who practice self-harm, e.g., cutting themselves, biting, burning, etc., expose themselves to infections or other severe problems like bleeding to death or fractures. Also, people who survive often have depression or other mental health problems. It also affects the community's health, and the family and friends of people who commit suicide may feel guilt, anger, shock, and depression (CDC, 2010). Action needs to be taken because suicide is a serious problem that leaves the rest of the community hopeless and depressed. The general aim of this study was to determine the various risk factors that lead to self-harm and suicidal ideation among Babcock University undergraduates. The factors addressed in this study were the environmental, social, and intrapersonal factors. Two research hypotheses were also used to check for an association between variables. The findings thereof may assist in raising awareness of the problem of suicidal behavior and promote research, resources, and prevention efforts in the mental health area in under-resourced and developing countries. 


\section{METHODOLOGY}

The data were collected using a cross-sectional descriptive survey. The study was conducted amongst undergraduates at Babcock University. Formal approval was obtained from the Babcock University Health and Research Ethics Committee (BUHREC) to ensure the safety of participants and regulate the procedure that was carried out. The instrument for this study was a well-structured questionnaire that contained questions that reflected the stated objectives of this study. The inclusion criteria for this study were all undergraduates, while exclusion criteria were pre-degree, law, and post-graduate students. The total number of distributed questionnaires was 400. The questionnaires were distributed according to the various halls' capacity and the availability of the consenting students in the halls. The questionnaires were shared in five days from March 1, 2019 to March 5, 2019. Eight trained research assistants were used to aid the distribution representing each hall of residence. The challenges encountered during the distribution of the questionnaires included people's compliance towards filling the questionnaire. Since consent was needed before administering the questionnaires, they were given to other consenting individuals. Only 398 copies of the 400 questionnaires which were distributed were retrieved. The supervisors checked the data collected to ensure accurate data. The data collected was coded and analyzed using the statistical package for social sciences [SPSS] version 21.0. Frequency tables were used to present results in percentages. The mean values were presented as mean \pm standard error for frequency parameters. ANOVA was used to examine the relationship between categorical and continuous variables, while regression was used to determine the strength of association.

\section{Study variables}

The independent variables used in this study were the environmental, social, and intrapersonal factors, while the dependent variable was suicidal ideation and self-harm.

\section{RESULTS}

A total of 400 participants were recruited in the study designed to explore the risk factors associated with suicidal ideation and self-harm among students in Babcock University, Ogun State. The participants were recruited from the undergraduate section of the university. The response rate upon retrieval of the instrument was $99.5 \%$ (398).

\section{Sociodemographic Characteristics of the Participants}

The respondents were undergraduate students of Babcock University. The results showed that the mean (SD) age was 19.78 (2.664), with 69.8\% (278) of the participants within the adolescence (15-20) age group (Table 1). The distribution of participants showed that $46.0 \%$ (183) of the participants were males while $54.0 \%$ (215) were females. The majority of the respondents were singles $(94.7 \%$; 377) and Christians $(77.9 \% ; 310)$ (Table 4.1). About half $(50.5 \% ; 201)$ were from the Yoruba ethnic group (Table 1), with one-third $(135 ; 33.9 \%)$ in the fourth year of study (Table 2). Over two-thirds $(68.3 \%$; 272) of the respondents were currently living with both of their parents, while only $23(5.8 \%)$ were living with one parent and a stepparent (Table 2). 
African Journal of Health, Nursing and Midwifery

ISSN: 2689-9418

Volume 4, Issue 6, 2021 (pp. 29-42)

www.abjournals.org

Table 1: Distribution of Sociodemographic Characteristics of Respondents: Age, Gender, Marital Status, and Ethnicity

\begin{tabular}{|c|c|c|}
\hline \multirow[b]{2}{*}{ Variables } & \multicolumn{2}{|c|}{ Frequency } \\
\hline & $\mathbf{N}$ & $\%$ \\
\hline \multicolumn{3}{|l|}{ Age } \\
\hline $15-20$ & 278 & 69.8 \\
\hline $21-25$ & 113 & 28.4 \\
\hline $26-30$ & 5 & 1.3 \\
\hline $31-35$ & 0 & 0.0 \\
\hline $36-40$ & 2 & 0.5 \\
\hline Total & 398 & 100 \\
\hline Mean (SD) & \multicolumn{2}{|c|}{$19.78(2.664)$} \\
\hline \multicolumn{3}{|l|}{ Gender } \\
\hline Male & 183 & 46.0 \\
\hline Female & 215 & 54.0 \\
\hline Total & 398 & 100 \\
\hline \multicolumn{3}{|l|}{ Marital Status } \\
\hline Single & 377 & 94.7 \\
\hline Married & 10 & 2.5 \\
\hline Divorced/Separated & 11 & 2.8 \\
\hline Total & 398 & 100 \\
\hline \multicolumn{3}{|l|}{ Ethnicity } \\
\hline Yoruba & 201 & 50.5 \\
\hline Igbo & 122 & 30.7 \\
\hline Hausa & 37 & 9.3 \\
\hline Others & 38 & 9.5 \\
\hline Total & 398 & 100 \\
\hline
\end{tabular}


Table 2: Distribution Sociodemographic Characteristics of Respondents: Religion, Level of Study and Living Condition

\begin{tabular}{ccc}
\hline & \multicolumn{2}{c}{ Frequency } \\
Variables & $\mathbf{N}$ & $\mathbf{\%}$ \\
\hline Religion & 311 & 78.1 \\
Christianity & 81 & 20.4 \\
Islam & 6 & 1.5 \\
Others & $\mathbf{3 9 8}$ & $\mathbf{1 0 0}$ \\
Total & & \\
& & \\
Level of Study & 74 & 18.6 \\
100 & 61 & 153 \\
200 & 88 & 22.1 \\
300 & 135 & 33.9 \\
400 & 27 & 6.8 \\
500 & 13 & 3.3 \\
600 & $\mathbf{3 9 8}$ & $\mathbf{1 0 0}$ \\
Total & & \\
& & \\
Living Condition & 272 & 68.3 \\
With both parents & 72 & 18.1 \\
With one parent & 31 & 7.8 \\
With other family members & 23 & 5.8 \\
With one parent and a stepparent & $\mathbf{3 9 8}$ & $\mathbf{1 0 0}$ \\
Total & &
\end{tabular}

\section{Environmental Factors Influencing Suicide Ideation and Self-Harm}

The environmental factors which influence the ideation of suicide and attempting self-harm were measured using a 7 -item Likert scale. About a quarter of the respondents $(24.2 \%$; 96) reported that at least one of their family members have had suicidal thoughts or engaged in self-harm. The proportion of respondents who reported that their parents believed suicidal ideation was demonic was $45.3 \%$ (184), while only 73 (20.8\%) respondents reported feeling safe at home. The respondents who reported that their parents' separation had caused emotional breakdown were about one-third of the total population $(120 ; 30.2 \%)$. Responses were coded into two groups and measured on a 21-point rating scale with a mean (SD) of 13.38 (3.458). 
Table 3: Distribution of Respondents' Environmental Influences on Suicidal Ideation and Self-harm

\section{Variables}

$1 \quad$ At least one of my family members have had suicidal thoughts or engaged in self-harm

2 Anytime I think of my parents' divorce or separation, I break down emotionally

3 The available support services are not youthfriendly

$4 \quad$ My parents believe that suicidal ideation is demonic.

$5 \quad$ I feel safe at home

6 My parents' relationship with me is cold

$7 \quad$ I have access to lethal means such as pills.

\begin{tabular}{|c|c|c|c|}
\hline \multicolumn{4}{|c|}{ Frequency } \\
\hline \multicolumn{2}{|c|}{ Yes } & \multicolumn{2}{|c|}{ No } \\
\hline $\mathbf{N}$ & $\%$ & $\mathbf{N}$ & $\%$ \\
\hline 96 & 24.2 & 302 & 75.8 \\
\hline 120 & 30.2 & 278 & 69.8 \\
\hline 219 & 55.1 & 179 & 44.9 \\
\hline 184 & 45.3 & 214 & 53.8 \\
\hline 73 & 20.8 & 315 & 79.2 \\
\hline 123 & 30.9 & 275 & 69.1 \\
\hline 108 & 27.2 & 290 & 62.8 \\
\hline
\end{tabular}

\section{Social Factors Influencing Suicide Ideation and Self-Harm}

The social factors which influenced young people's suicide ideation and self-harm practices were measured using a 9-item scale. The questions asked were presented on a Likert scale and computed to a 27-point scale. About half of the respondents indicated high self-esteem, while $38.5 \%$ (153) reported that they had felt left out by friends or family during the six months preceding the study (Table 4). The respondents' mean (SD), as shown in Table 4 for the social factors, was 17.15 (5.772).

\section{Intrapersonal Factors Influencing Suicide Ideation and Self-Harm}

The intrapersonal factors which could influence the ideation of suicide and self-harm were assessed through a 10 -item Likert scale. Over half of the respondents $(205 ; 51.5 \%)$ reported to have become easily annoyed or irritable during the past six months, while only $76(19.1 \%)$ indicated that they had had arguments, fights, or gotten into trouble with their friends or family members. A fair proportion $(168 ; 42.2 \%)$ of the respondents had experienced sadness or hopelessness daily for about 2-3 weeks or more while 195 (49.0\%) had felt sad to the extent of deriving no pleasure or fulfillment in performing their daily activities (Table 5). The items were computed to 30 points with a mean of 18.78 (7.658) (Table 5). 
Table 4: Distribution of Respondents' Social Factors Influencing Suicide Ideation and Self-harm

\begin{tabular}{|c|c|c|c|c|c|}
\hline & \multirow{3}{*}{ Variables } & \multicolumn{4}{|c|}{ Frequency } \\
\hline & & \multicolumn{2}{|c|}{ Yes } & \multicolumn{2}{|c|}{ No } \\
\hline & & $\mathbf{N}$ & $\%$ & $\mathbf{N}$ & $\%$ \\
\hline 1 & $\begin{array}{l}\text { My parents do not listen to me when I talk } \\
\text { about my problems }\end{array}$ & 143 & 35.9 & 255 & 64.1 \\
\hline 2 & $\begin{array}{l}\text { I have been bullied on one or more days in } \\
\text { the past } 30 \text { days }\end{array}$ & 92 & 23.1 & 306 & 76.9 \\
\hline 3 & $\begin{array}{l}\text { I have been sexually abused one or more } \\
\text { times in my life }\end{array}$ & 115 & 28.9 & 283 & 71.1 \\
\hline 4 & $\begin{array}{l}\text { I have felt left out by friends or family } \\
\text { during the past six months }\end{array}$ & 153 & 38.5 & 245 & 61.5 \\
\hline 5 & $\begin{array}{l}\text { I get little or no social support from my } \\
\text { family and friends }\end{array}$ & 113 & 28.4 & 285 & 71.6 \\
\hline 6 & I don't like associating with my peers & 137 & 34.4 & 261 & 65.6 \\
\hline 7 & I feel I have a high self-esteem & 210 & 52.8 & 188 & 47.2 \\
\hline 8 & I don't feel safe with family & 89 & 22.4 & 309 & 77.6 \\
\hline 9 & $\begin{array}{l}\text { I never get the attention I need from family } \\
\text { and friends }\end{array}$ & 126 & 31.6 & 272 & 68.4 \\
\hline
\end{tabular}

Table 5: Distribution of Respondents' Intrapersonal Factors Influencing Suicide Ideation and Self-harm

\section{Variables}

$1 \quad$ I have felt so sad or hopeless almost every day for two weeks or more in a row

2 I have felt so sad that I derived little to no fulfillment from performing my day to day activities

3 I had at least one drink containing alcohol on one or more days during the past 30 days

4 I have gotten into trouble with family or friends, school, or gotten into fights as a result of drinking alcohol

$5 \quad$ I have thought of taking my own life during the past six months

6 The loss of a loved one has disrupted my sleep pattern

\begin{tabular}{ccccc}
\multicolumn{4}{c}{ Frequency } \\
\hline \multicolumn{3}{c}{ Yes } & \multicolumn{3}{c}{ No } \\
N & $\%$ & N & $\%$
\end{tabular}

$\begin{array}{llll}168 & 42.2 & 230 & 57.8\end{array}$

$195 \quad 49.0 \quad 203 \quad 51.0$

$\begin{array}{llll}91 & 22.9 & 307 & 77.1\end{array}$

$\begin{array}{llll}76 & 19.1 & 322 & 80.9\end{array}$

$\begin{array}{llll}109 & 27.4 & 289 & 72.6\end{array}$

$\begin{array}{llll}143 & 35.9 & 255 & 64.1\end{array}$ 


\begin{tabular}{clcccc}
\hline 7 & I become easily annoyed and irritable & 205 & 51.5 & 193 & 48.5 \\
8 & I feel lonely most of the time & 199 & 50.0 & 199 & 50.0 \\
9 & I feel so much pain & 139 & 35.0 & 259 & 65.0 \\
10 & I have the urge to play with objects or sharps & 92 & 23.1 & 306 & 76.9 \\
\hline
\end{tabular}

\section{The Pattern of Self-harm among Respondents}

About a quarter of the respondents $(106 ; 26.6 \%)$ reported having thought of and considered suicide, while only $20.4 \%$ (81) had harmed themselves. The reported methods of self-harm among the respondents were drug overdose $(35 ; 8.8 \%)$, cutting the skin $(37 ; 9.3 \%)$; scratching the skin $(21 ; 5.3 \%)$, and other methods $(9 ; 2.3 \%)$ which were not listed (Table 6$)$. Among the respondents who reported having harmed themselves before, 74 students had done so in the past six months preceding the study, while $71(17.8 \%)$ had felt pain during the self-harm episodes. The proportion of respondents who reported to have had company with them while they were cutting themselves were 68 (17.1\%) (Table 6).

Table 6: Pattern of Suicide Ideation and Self-harm among Respondents

\begin{tabular}{|c|c|c|c|c|c|}
\hline \multirow{3}{*}{$\mathbf{S} / \mathbf{N}$} & \multirow{3}{*}{ ITEM } & \multicolumn{4}{|c|}{ Frequency } \\
\hline & & \multicolumn{2}{|r|}{ YES } & \multicolumn{2}{|c|}{ NO } \\
\hline & & $\mathbf{N}$ & $\%$ & $\mathbf{N}$ & $\%$ \\
\hline $\mathbf{1}$ & Suicide ideation & 106 & 26.6 & 292 & 73.4 \\
\hline 2 & Self-harm & 81 & 20.4 & 317 & 79.6 \\
\hline \multirow[t]{5}{*}{3} & Methods of self-harm* & & & & \\
\hline & Drug overdose & 35 & 8.8 & 363 & 91.2 \\
\hline & Cutting the skin & 37 & 9.3 & 361 & 90.7 \\
\hline & Scratching the skin with items & 21 & 5.3 & 377 & 94.7 \\
\hline & Others & 9 & 2.3 & 389 & 97.7 \\
\hline 4 & Self-harm in the last six months & 74 & 18.6 & 324 & 81.4 \\
\hline 5 & Pain during self-harm & 71 & 17.8 & 327 & 82.2 \\
\hline 6 & Company during self-harm & 68 & 17.1 & 330 & 82.9 \\
\hline
\end{tabular}


Relationship between Suicide Ideation, Self-harm, and Selected Sociodemographic Characteristics: Gender and Living Condition

Table 7 shows the test results to determine the relationship between gender and the individuals the students lived with on suicide ideation. As shown, among the participants who reported to have had suicide ideation, 63 were males while 43 of the students were females. The test type used was a Chi-square test which generated a statistically significant relationship ( $p>0.01$ ). More participants who indicated to be living with both parents have had suicide ideation, while only 12 students living with one parent and a stepmom/dad have had suicide ideation (Table 7).

Forty-three male students reported having harmed themselves, while 38 females indicated the same. There was no statistical difference $(p=0.170)$ observed within these groups; hence, the gender of the students does not determine the students' self-harm practices (Table 8). However, the individuals the students lived with were shown to influence the self-harm practices $(\mathrm{p}>$ $0.01)$.

Table 7: Relationship between Suicide Ideation and Specific Sociodemographic Characteristics: Gender and Family Structure

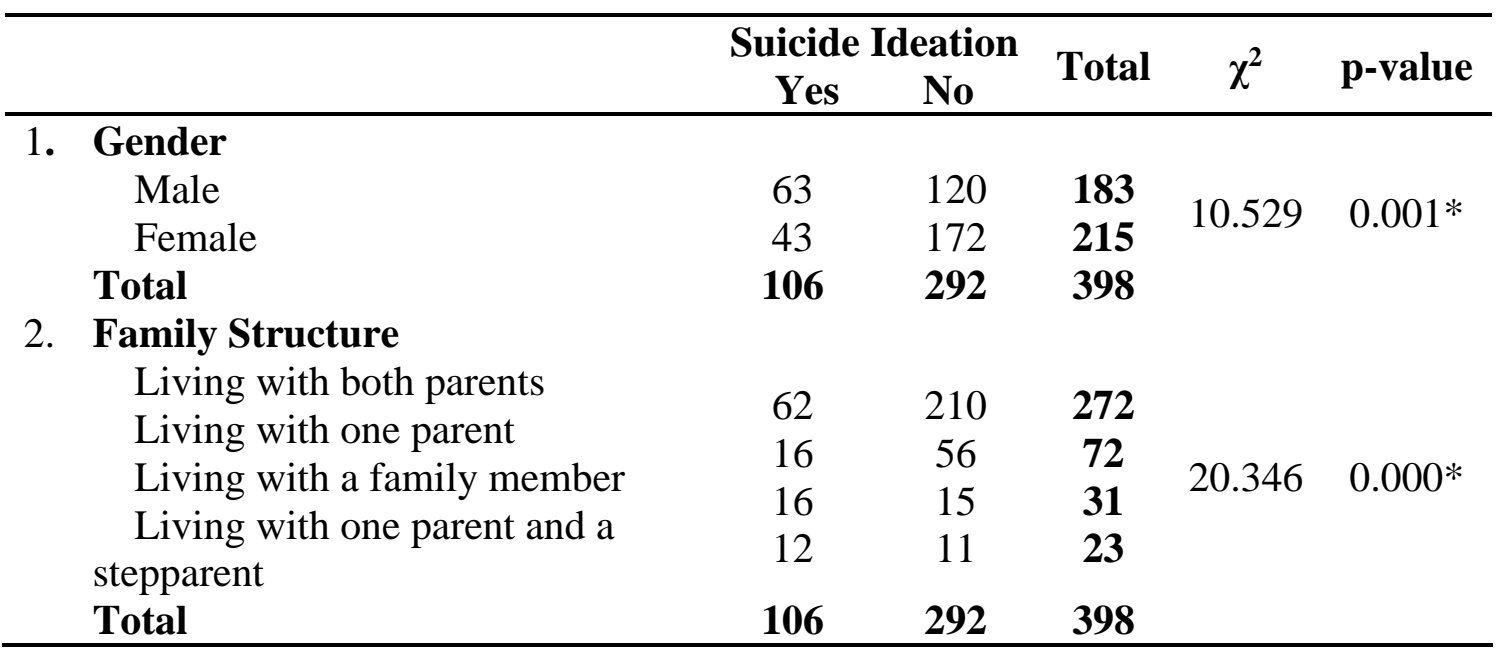

*significant at $\mathrm{p}>0.05$

Table 8: Relationship between Self-harm and Specific Sociodemographic Characteristics: Gender and Family Structure

\begin{tabular}{ccccccc}
\hline & \multicolumn{2}{l}{ Self-harm } & Total & $\chi^{\mathbf{2}}$ & p-value \\
& Yes & No & & & \\
\hline 1. Gender & & & & & \\
Male & 43 & 140 & $\mathbf{1 8 3}$ & 2.068 & 0.170 \\
Female & 38 & 177 & $\mathbf{2 1 5}$ & & \\
Total & $\mathbf{8 1}$ & $\mathbf{3 1 7}$ & $\mathbf{3 9 8}$ & & \\
\hline
\end{tabular}




\section{Family Structure}

$\begin{array}{llllll}\text { Living with both parents } & 44 & 228 & \mathbf{2 7 2} & 20.948 & 0.000^{*} \\ \text { Living with one parent } & 14 & 58 & \mathbf{7 2} & & \\ \text { Living with a family member } & 15 & 16 & \mathbf{3 1} & & \\ \text { Living with one parent and a } & 8 & 15 & \mathbf{2 3} & & \end{array}$
stepparent

\section{$\begin{array}{llll}\text { Total } & 81 & 317 & 398\end{array}$}

*significant at $\mathrm{p}>0.05$

\section{Factors Influencing Suicide Ideation among Students}

Correlation and linear regression analyses were used to test if the environmental, social, and intrapersonal factors had statistical relationships with and predicted the ratings of suicide ideation among the adolescents. Table 9 summarizes the descriptive statistics and analysis results. Environmental factors were measured on a 21-point rating scale, social factors on a 27point rating scale, and intrapersonal factors on a 30-point rating scale (Table 11). A positive significant correlation was found between the environmental factors and suicide ideation; hence, a regression analysis was conducted. Regression analysis showed a statistical relationship between environmental factors and suicide ideation $\left(\mathrm{F}_{(1,396)}=68.520, \mathrm{p}<0.01\right)$ with a $\mathrm{R}^{2}$ of 0.148 . This result indicates that environmental factors account for $14.8 \%$ of the variation in suicide ideation. Likewise, social $\left(\mathrm{F}_{(1,396)}=120.566, \mathrm{p}<0.01, \mathrm{R}^{2}=0.233\right)$ and intrapersonal factors $\left(\mathrm{F}_{(1,396)}=96.259, \mathrm{p}<0.01, \mathrm{R}^{2}=0.196\right)$ had significant regression relationship with suicide ideation. They account for $23.3 \%$ and $19.6 \%$ respectively of the variation in suicide ideation among the students

Table 9: Inferential Statistic Results between Suicide Ideation and Risk Factors (Environmental, Social, and Intrapersonal)

\begin{tabular}{clccccc}
\hline S/N & \multicolumn{1}{c}{ Variable } & df & $\mathbf{F}$ & $\boldsymbol{\beta}$ & $\mathbf{R}^{\mathbf{2}}$ & p-value \\
\hline $\mathbf{1}$ & Environmental factors & 396 & 68.520 & 0.384 & 0.148 & $0.000^{*}$ \\
$\mathbf{2}$ & Social factors & 396 & 120.566 & 0.483 & 0.233 & $0.000^{*}$ \\
$\mathbf{3}$ & Intrapersonal factors & 396 & 96.259 & 0.442 & 0.196 & $0.000^{*}$ \\
\hline
\end{tabular}

*significant at $\mathrm{p}>0.05$

\section{Factors Influencing Self-harm among Students}

Correlation analysis was carried out to determine if statistical relationships exist between students' environmental, social and intrapersonal factors and self-harm. The confirmation of a positive correlation relationship determined the necessity for a linear regression analysis to predict the amount of variation in self-harm caused by these factors. Table 10 summarizes the descriptive statistics and analysis results. A significant regression relationship was found between environmental factors and suicide ideation $\left(\mathrm{F}_{(1,396)}=74.579\right.$, $\left.\mathrm{p}<0.01\right)$ with a $\mathrm{R}^{2}$ of 
0.158. Also, the social $\left(\mathrm{F}_{(1,396)}=93.695, \mathrm{p}<0.01, \mathrm{R}^{2}=0.191\right)$ and intrapersonal factors $\left(\mathrm{F}_{(1,396)}\right.$ $\left.=92.560, \mathrm{p}<0.01, \mathrm{R}^{2}=0.181\right)$ showed significant regression relationship with self-harm.

Table 10: Inferential Statistic Results between Self-harm and Risk Factors (Environmental, Social, and Intrapersonal)

\begin{tabular}{clccccc}
\hline S/N & \multicolumn{1}{c}{ Variable } & df & $\mathbf{F}$ & $\boldsymbol{\beta}$ & $\mathbf{R}^{\mathbf{2}}$ & p-value \\
\hline $\mathbf{1}$ & Environmental factors & 396 & 74.579 & 0.398 & 0.158 & $0.000^{*}$ \\
$\mathbf{2}$ & Social factors & 396 & 93.695 & 0.437 & 0.191 & $0.000^{*}$ \\
$\mathbf{3}$ & Intrapersonal factors & 396 & 92.560 & 0.435 & 0.189 & $0.000^{*}$ \\
\hline
\end{tabular}

*significant at $\mathrm{p}>0.05$

Table 11: Summary of Descriptive Statistics of Variables.

\begin{tabular}{clcc}
\hline S/N & \multicolumn{1}{c}{ Variable } & Points & Mean $($ SD) \\
\hline $\mathbf{1}$ & Environmental factors & 21 & $13.38(3.458)$ \\
$\mathbf{2}$ & Social factors & 27 & $17.15(5.772)$ \\
$\mathbf{3}$ & Intrapersonal factors & 30 & $18.78(7.658)$ \\
\hline
\end{tabular}

\section{Test of Hypotheses}

Hypothesis 1: The gender distribution of students at Babcock University influences suicide ideation and self-harm practices.

As shown in Table 7, there is a statistical difference $(\mathrm{p}=0.001)$ in the gender distribution of the students who had suicide ideation. The result implies that gender has a significant effect on the suicide ideation of students at Babcock University. However, the test to determine the relationship between gender and self-harm revealed no statistical significance $(P=0.170)$. This result indicates that gender did not influence the students' self-harm practices (Table 8).

Hypothesis 2: Family has an influence on suicide ideation and self-harm practices among students at Babcock University.

As shown in Table 7, there is a significant relationship between the parents' spousal relationship and the suicide ideation practices of students. At $p>0.01$ level of significance, the relationship is statistically significant. Hence, the nature of the parents' spousal relationship influences the level of suicide ideation among the students (Table 7). Likewise, self-harm among the students was shown to be influenced by the parents' spousal relationship ( $p>0.01)$ (Table 8).

\section{DISCUSSION}

The study focused on the risk factors for suicide ideation and self-harm among undergraduate students in Babcock University, Ogun State, Nigeria. The results from the study provide insight into the environmental, social, and intrapersonal factors which could influence the rates of 
suicide ideation and self-harm among students in tertiary institutions. The participants were recruited from the undergraduate school of Babcock University. The response rate for the study was quite good.

The respondents were primarily young people with a mean (SD) age of 19.78 (2.664). This age group has been reported to be susceptible to higher risks of committing suicide. This could be due to some of the developmental challenges among young people, categorically adolescents. The stage is a stormy one and is a genuine risk factor for mental health challenges in adulthood. WHO (2016) reported that more suicide cases are being reported in low and middle-income countries. The World Health Organization (2016) reported that suicide is one of the leading causes of death among people aged 15-29. The present analysis is built on the public concern for self-harm practices and suicide attempts among young people in this community. It is noteworthy to mention that a few cases of self-harm and attempted suicide had been reported in recent years within the study population. An estimated $26.6 \%$ of the undergraduate students currently had suicide ideation. The present results are of great concern given that suicide is a network that involves a series of routes that begins with the ideation, progresses to planning, and finally, to the attempt. Mann et al. (2005) stated that the success of suicide depends on ideation and planning. The effects of suicide and self-harm ideation could be long-term with links to depression and morbidity (Clark \& Curry, 2009; Glassman \& Shapiro, 1998).

As is typical of gender imbalance in tertiary institutions, most of the respondents recruited for this study were females and single. The results show that the gender of the students was statistically related to the rates of suicide or its ideation. The proportion of males who had suicide ideation or intentionally harmed themselves was more than that of females. This can be supported by the research results conducted by Neeeleman, De Graaf and Vollebergh (2009), which stated that the suicidal process develops faster in males than females. In contrast to this, Evans, Hawton, Rodham and Deeks (2005) reported that the ideation of suicide is more prevalent in females than males. Their study results showed that females attempted suicide more than males, but the latter would utilize lethal means compared to the females. This could be because females are more emotionally expressive than their male counterparts. The factors tested in this research (environmental, social, and intrapersonal) significantly correlate with suicide ideation and self-harm. The environment has a significant influence on suicidal behavior, which is very evident in the first stage of the suicide process. This could progress to become more independently linked with mental illness and depression. Low-income families and social environments seem to influence suicidal behaviors and self-harm practices. Brent $e t$ al. (1999) reported that discord within families was the most common determinant of completed suicide in a study. About half of the respondents in this study believed that the available support services for young people were not friendly. The perception of young people about health services is a strong determinant of the help-seeking behaviors of this group of people. Many young people do not seek help because they feel the services are judgmental and biased. This corroborates reports of a study carried out by Nada-Raja, Morrison and Skegg (2013), which reported that half of the young people who practiced deliberate self-harm sought help from professionals and rated the care poorly.

Intrapersonal factors were significantly related to suicide ideation and self-harm in this study. About half of the respondents reported feeling lonely or irritable many times. Loneliness could play an essential role in enforcing suicide ideations during adolescence. A study conducted by Swahn et al. (2010) confirmed the contribution of loneliness to suicide ideation and attempt. Almost half of the students reported having low self-esteem and derived little or no fulfillment 
in everyday activities. The way young people perceive themselves could be a significant contributory factor to the idea of suicide and eventual attempt or completion. Self-esteem has been established to correlate with suicide among young people by several studies worldwide (Hawton, Saunders \& O'Connor, 2012; King et al., 2001). Loneliness and social support are significant predictors of adolescent depression and suicide ideation (Qualter, Brown, Munn \& Rotenberg, 2010; McKinnon, Gariépy, Entenaca \& Elgar, 2016).

\section{CONCLUSION}

Suicide ideation and self-harm are major public health issues in young people across the world. Identifying the risk factors to suicide ideation and self-harm is essential in curbing the growing menace. Several studies have been carried out in Nigeria on suicide, but there is a paucity of data on the intrapersonal factors contributing to the high rates. The information obtained from this study can help in intervention and prevention services to reduce suicide rates. Mental health facilities should be made accessible, affordable, and friendly to adolescents.

\section{Future Research}

Future research should focus on further identifying other risk factors that contribute to suicide ideation and deliberate self-harm among young people. Psychological and psychosocial interventions should be conducted to reduce the impact of suicide ideation on young people.

\section{REFERENCES}

Brent, D. A., Baugher, M., Bridge, J., Chen, T., \& Chiappetta, L. (1999). Age- and sexrelated risk factors for adolescent suicide. Journal of American Academy Child Adolescent Psychiatry, 1497-1505.

Clarke, D., \& Currie, K. (2009). Depression, anxiety and their relationship with chronic diseases: a review of the epidemiology, risk and treatment evidence. Medical Journal of Austrailia , 54-60.

Evans, E., Hawton, K., Rodham, K., \& Deeks, J. (2005). The prevalence of suicidal phenomena in adolescents: A systematic review of population-based studies. Suicide and Life-Thretening Behaviour, 239-249.

Glassman, A., \& Shapiro, P. (1998). Depression and the course of coronary artery disease. Am J Psychiatry, 4-11.

Hawton, K., Saunders, K., \& O'Connor, R. (2012). Self-harm and suicide in adolescents . Lancet , 2373-2382. doi: doi: http://dx.doi.org/10.1016/ S0140-6736(12)60322-5

King, R., Schwab-Stone, M., Flisher, A., Greenwald, S., Kramer, R., \& Goodman, S. (2001). Psychosocial and risk behavior correlates of youth suicide attempts and suicidal ideation. Journal of the American Academy of Child and Adolescent Psychiatry, 837846. doi:doi: http://dx.doi.org/10.1097/00004583-200107000- 00019

Kwangu, \& Mwenya. (2017). Suicidal Ideation Prevalence and Its Associated Factors among School-Going Adolescents in Pakistan. International Public Health Journal, 401. 
Madge, N., Hawton, K., \& McMahon, E. (2011). Psychological characteristics, stressful life events and deliberate self-harm: findings from the Child \& Adolescent Self-harm in Europe (CASE) study. European Child Adolescent Psychiatry, 499-508.

Mann, J., Apter, A., Bertolote, J., Beautrais, A., Currier, D., Haas, A., \& Hendin, H. (2005). Suicide prevention strategies. JAMA Network. JAMA Network, 2064-2074.

McKinnon, B., Gariépy, G., Sentenaca, M., \& Elgar, F. (2016). Adolescent suicidal behaviours in 32 low- and middle-income countries. Bull World Health Organization, 340-350. doi:doi: http://dx.doi.org/10.2471/BLT.15.163295

Miller, A., Renshaw, K., Esposito-smythers, C., \& Weismoore, J. (2013). The relationhip between child maltreatment and adolescent review and critical examination of the literature. Clinical Child and Family Psychology Review, 146-172.

Nada-Raja, S., Morrison, D., \& Skegg, K. (2013). A population-based study of help-seeking for self-harm in young adults. Australian and New Zealand Journal of Psychiatry, 600605.

Neeleman, J., De-Graaf, R., \& Vollebergh, W. (2009). The suicidal process: Prospective comparison between early and later stages. Journal of Affective Disorders, 43-52.

Organization, W. H. (2016). Suicide Data. WHO. Retrieved from http://who.int/mental_health/prevention/suicide/suicideprevent/en/

Qualter, P., Brown, S., Munn, P., \& Rotenberg, K. (2010). Childhood loneliness as a predictor of adolescent depressive symptoms: an 8-year longitudinal study. European Child Adolescent Psychiatry. doi:http://dx.doi. org/10.1007/s00787-009-0059-y

Swahn, M., Bossarte, R., Eliman, D. M., Gaylor, E., \& Jayaraman, S. (2010). Prevalence and correlates of suicidal ideation and physical fighting: a comparison of students in Botswana,Kenya, Uganda, Zambia and the Unites States. International Public Health Journal.

World Health Organization (2016). Suicide Data. WHO. Retrieved from http://who.int/mental_health/prevention/suicide/suicideprevent/en/ 